\title{
Factors associated with surgical site infection among women undergoing obstetrics surgery at Felegehiwot Referral Hospital, Bahir Dar, Northwest Ethiopia: a retrospective cross-sectional study
}

\author{
Getnet Gedefaw ${ }^{1 *}$ (D) Azezu Asires², Shumiye Shiferaw² and Dagne Addisu ${ }^{3}$
}

\begin{abstract}
Background: Surgical site infections are one of the most common healthcare-associated infections in low- and middle-income countries, which cause prolonged hospital stays and increase patient susceptibility to other nosocomial infections. Hence, this study aimed to determine the magnitude and associated factors of surgical site infections among women who underwent obstetric surgeries in Felegehiwot Specialized Hospital, Amhara, Bahir Dar, Ethiopia in 2018.

Methods: An institution-based retrospective cross-sectional study was conducted from March 1 to April 30, 2018, in Felegehiwot Specialized Hospital. Retrospective card review was done on 447 women who underwent obstetric surgeries at Felegehiwot Hospital from September 1, 2016, to August 30, 2017. The systematic sampling technique was used to select patient medical cards.

Results: This study revealed that the prevalence of surgical site infection was $9.4 \%$ with $[95 \% \mathrm{Cl}=6.9 \%, 12.1 \%]$. Chorioamionitis[AOR $=3.73 ; 95 \% \mathrm{Cl}=1.22,11.4]$, pregnancy-induced hypertension[AOR $=6.4,95 \% \mathrm{Cl}=2.26,18$. $2]$, diabetes mellitus $[A O R=3.99 ; 95 \% \mathrm{Cl}=1.03,15.5]$, thickness of subcutaneous tissue $>2 \mathrm{~cm}[\mathrm{AOR}=4.05 ; 95 \%$ $\mathrm{Cl}=1.75,9.4]$, duration of labor $>24 \mathrm{~h}[\mathrm{AOR}=5.25 ; 95 \% \mathrm{Cl}=2.32,11.8]$, and urinary tract infections $[\mathrm{AOR}=7.78$; $95 \% \mathrm{Cl}=1.4,43.25]$ were the predictors of surgical site infection.

Conclusion: It has been revealed that the magnitude of the surgical site infection rate following obstetric surgery was higher compared to the standard CDC guidelines of surgical site infection. Duration of labor stays more than $24 \mathrm{~h}$, chorioamnionitis, pregnancy-induced hypertension, urinary tract infections, diabetes mellitus, and thickness of subcutaneous tissue more than $2 \mathrm{~cm}$ were associated with surgical site infections. In addition to complication readiness, birth preparedness, and setting their antenatal care follow-up at the hospital with special and targeted services can reduce the magnitude of surgical site infection.
\end{abstract}

Keywords: Felegehiwot, Surgical site infection, Ethiopia

\footnotetext{
* Correspondence: gedefawget@gmail.com

'Department of Midwifery, Faculty of Health Sciences, Woldia University,

Woldia, Ethiopia

Full list of author information is available at the end of the article
}

(c) The Author(s). 2018 Open Access This article is distributed under the terms of the Creative Commons Attribution 4.0 International License (http://creativecommons.org/licenses/by/4.0/), which permits unrestricted use, distribution, and reproduction in any medium, provided you give appropriate credit to the original author(s) and the source, provide a link to the Creative Commons license, and indicate if changes were made. The Creative Commons Public Domain Dedication waiver (http://creativecommons.org/publicdomain/zero/1.0/) applies to the data made available in this article, unless otherwise stated. 


\section{Background}

Infection is one of the most common causes of maternal mortality and morbidity in obstetrics [1].

Surgical site infections (SSIs) are infections that occur at or near surgical incision within 30 days of operation or after 1 year if an implant is placed [2].

According to the Center for Disease Control and Prevention (CDC) surgical site infections are classified as being either incision (superficial and deep) or organ space (any part of the anatomy) that must develop within 30 days of operation and based on operative wounds clean, clean-contaminated, contaminated, and dirty wounds [3, 4].

Globally, SSIs are potential complications associated with any type of surgical procedure. Even though SSIs are among the most preventable HAIs, they still symbolize a significant burden in terms of patient morbidity and mortality. High rates of surgical site infection following obstetric surgeries were reported in several African countries [5, 6].

Pregnant women are at risk of infection during labor and delivery. Among surgical cases in obstetrics; Surgical Site Infections (SSIs) are the fourth most common nosocomial infections [7].

Surgical site infection causes a substantial risk to patients and financial loses for health systems because the multi-factorial causes achieving a measurable and sustained reduction in SSI risk is challenging [5].

Surgical site infections are preventable complications which impose a significant burden in terms of patient morbidity, mortality and increased the cost of treatment. Patients who develop SSIs are up to $60 \%$ more likely to spend their time in an intensive care unit, readmitted to hospital and more likely to die compared with patients without surgical site infections [6].

Surgical site infection exemplifies a substantial burden to the health system comprising an increased length of hospitalization and costs of post-discharge care [8].

Despite enhancements in operating room practices, instrument sterilization methods, better surgical technique, and performing best efforts of infection prevention strategies, surgical site infections remain the main cause of hospital-acquired infections. Even though standard protocols of preoperative preparation and antibiotic prophylaxis were properly practiced, the rate of surgical site infection was increasing worldwide [9].

World Health Organization supported the implementation of SSI prevention and quality improvement intervention in all surgical departments in five African countries. Despite these interventions, Ethiopia situations did not improve the outcome of surgical site infection for the last surveillance report [5].

Even though the number of institutions and professionals were increased, the rate of surgical site infection following surgery in obstetrics is still high throughout the world, particularly in developing countries. Overall, there was no significant reduction in surgical site infections in Africa including Ethiopia [6].

Therefore, proper assessment on the magnitude and risk factors that predispose to surgical site infection after obstetrics surgery is essential for developing targeted interventions to reduce its occurrence and complications as well as reducing costs and length of patient stay in the hospital.

\section{Methods and materials Study setting}

This study was conducted at Bahir Dar Referral Hospital. Bahir Dar town is located in the Amhara region, $565 \mathrm{~km}$ from Addis Ababa. According to the Ethiopian central statistical agency report, the total population of the Bahir Dar town administration was 221,991 in 2007. Of this, 108,456 were male and 113,535 were female. There are 2 public hospitals and 10 health centers.

Felegehiwot Comprehensive, Specialized Hospital Department of Obstetrics and Gynecology has gynecology ward, maternity, high risk, postnatal, labor, and gynecology outpatient departments, and maternal and child health unit with a total of 82 beds. There are different laboratory units which are giving different services. These are microbiology and parasitological unit, chemistry unit, and general laboratory service unit. The hospital has an in-house laboratory in case of any laboratory investigations.

Felegehiwot Hospital has 9 consultant obstetricians and gynecologists, 35 obstetrics and gynecology residents, 5 general practitioners, 33 midwives, medical interns, and 17 clinical nurses. The hospital serves as a teaching hospital jointly with Bahirdar University College of medical and health science.

An institution-based retrospective cross-sectional study was conducted from March 1 to April 30, 2018, among women who underwent obstetric surgeries at Felegehiwot Specialized Referral Hospital from September 2016 to August 30, 2017. This study was aimed to determine possible risk factors for surgical site infections at Felege Hiwot Referral Hospital in Ethiopia.

\section{Inclusion criteria}

All cards of women who underwent obstetric surgeries at Felegehiwot Comprehensive Specialized Hospital.

\section{Exclusion criteria}

Women who died before the third postoperative days.

Women whose surgery was done in other healthcare facilities.

\section{Sample size and sampling procedure}

The minimum sample size was determined using a single population proportion formula $\left[n=\left[\left(Z_{\mathrm{a} / 2}\right)^{2 *} P(1-P)\right] / d^{2}\right]$ 
by assuming a 95\% confidence level of $Z$ a/2 $=1.96$, marginal of error $5 \%$, and proportion of surgical site infection of 9.4\% at Assela Referral Hospital. The final sample size was 131 for the first objective.

Based on the double population proportion formula using Epi info version 7.2 stat calc programs, the minimum sample size was determined. The final sample size was 447.

Overall, 2200 mothers underwent obstetrics and gynecology surgery over the last 1 year period. On average, 184 women underwent surgery per month. Among the 2200 women who underwent surgery, 709 had surgery for gynecologic indications (e.g., evacuation and curettage) and were excluded from our study. Finally complete and eligible charts became 1448. After establishing the sampling frame, $K$ (regular interval) was calculated by using the formula $=N / n$ which is total obstetrics surgery (1448) divided by the sample size (447) and it is approximately 3 . The first card (subject) was selected randomly by lottery method and then continued every $k$ th (third) value until the required numbers of samples were collected.

\section{Data collection instruments and procedure}

The data were collected using a pretested structured checklist from March 1 to April 30, 2018. All the variables of interest were assessed accordingly and the structured and pretested checklist was prepared in English. Two data collectors, who have BSc in midwifery and one supervisor has participated in the data collection process. Orientation was given for data collectors and supervisor on objectives and the way of data collection before starting the actual data collection. Data collectors were supervised daily, and all the collected data was checked daily by the supervisor.

About 22 (5\%) of pretest was done before the actual data collection time at Felegehiwot Referral Hospital to assure the quality of data and to evaluate the content validity of the documentation and face validity of the questionnaires.

Using card number of patients, data collectors were traced and collected data from systematically identified charts of women whose obstetric surgery were done from September 1, 2016 to August 30, 2017 at Felegehiwot Referral Hospital through checklists. Women who had obstetric surgeries from September 2016 to August 30, 2017 were enrolled using chart review retrospectively, and we consider surgical site infections those patients who were diagnosed as surgical site infection with the respective classifications based on the clinical examination which were made by gynecologists and gynecology, and obstetrics residents. Surgical site infections were detected after the patient was discharged based on the admission diagnosis and discharge summary. Patients whose surgeries are out of this hospital were excluded from the study due to lack of patients' chart.

\section{Operational definitions Obstetric surgeries}

A surgery performed on the abdomen of a pregnant woman for conditions associated with pregnancy, labor, or the puerperium which includes cesarean delivery, uterine repair, and abdominal hysterectomy with the respective indications excluding fetal or newborn surgery.

\section{Data processing and analysis}

The data were checked for completeness, inconsistencies, and then coded, entered using EPI data version 4.2. Then, the data cleaned and analyzed using SPSS version 23. Descriptive statistics were computed to determine frequencies and summary statistics (mean, standard deviation, and percentage). Data were presented using tables, graphs, and figures. Bivariate logistic regression analysis was done after dichotomizing the dependent variables. After checking associations of the variables, those with $p<0.2$ in bivariate analysis were processed to multi-variable logistic regression analysis to control confounding factors. $p$ value of $<0.05$ was used to express the statistical significance of the variables.

\section{Results}

\section{Socio-demographic characteristics}

A total of 447 women chart was enrolled in this study. The mean age of the women was 28.8 years (ranged from 18 to 45 years) with SD of \pm 5.9 years. More than half of the women $260(58.2 \%)$ lived in an urban area, and majority of them 438 (98\%) were married in this study area (Table 1).

\section{Medical-related characteristics}

From the total of 447 women, 47 (10.5\%) mothers developed pregnancy-induced hypertension and 22 (4. 9\%) mothers had anemia (Table 2).

\section{Obstetric-related factors}

From the total of 447 women undergoing operation, more than three fourth $(76.1 \%)$ of them had antenatal care. About 298 (66.7\%) of them had membrane ruptured prior to the surgery. Of these, 171 (57.4\%) of them had rupture of membrane more than $12 \mathrm{~h}$ before operation (Table 3 ).

\section{Anesthesia- and operation-related characteristics}

All of the respondents were given antibiotics prophylaxis within $30 \mathrm{~min}$ before operation. Regarding their preoperative hematocrit, $352(78.7 \%)$ of them had hematocrit greater than $30 \%$ with a mean of $32.6( \pm 5.6)$. More than half $(250,55.9 \%)$ was attended by resident year 3 and 407 (91.1\%) of skin closure technique was subcuticular. About 401 (89.7\%) of operation procedure was finished less than $1 \mathrm{~h}$, and 414 (92.6\%) of them estimated blood loss was less than or equal to $1 \mathrm{~L}$ (Table 4). 
Table 1 The distribution of socio-demographic characteristics of women having obstetrics surgeries in obstetrics ward of FHRH, Ethiopia, $2018(n=447)$

\begin{tabular}{lll}
\hline Characteristics & Frequency & Percent \\
\hline Age & 16 & 3.6 \\
$\leq 19$ & 341 & 76.3 \\
$20-34$ & 90 & 20.1 \\
$\geq 35$ & & \\
Religion & 370 & 82.8 \\
$\quad$ Orthodox & 68 & 15.2 \\
Muslim & 9 & 2 \\
Protestant & & \\
Residence & 260 & 58.2 \\
Urban & 187 & $41 . .8$ \\
Rural & & \\
Marital status & 438 & 98 \\
Married & 9 & 2 \\
$\quad$ Others* & &
\end{tabular}

\section{Prevalence of surgical site infection}

The overall magnitude of surgical site infection in this study was 42 (9.4\%). Of these, 30 (6.7\%) of women underwent cesarean section followed by an abdominal hysterectomy and uterine repair, which account 8 (1.8\%) and $4(0.9 \%)$ respectively. Regarding the type of surgical site infection, about $28(66.7 \%)$ of them were superficial and $14(33.3 \%)$ of them were deep. Of 42 SSI women, 33 (78.6\%) of surgical site infection were detected after discharge. Whereas 9 (21.4\%) of them were detected before discharge.

\section{Indication of cesarean section}

Among mothers who underwent cesarean section, non-reassuring fetal heart rate pattern 60 (15.7\%)was the most common indication followed by cephalopelvic disproportion and latent first stage of labor with grade 3 meconium-stained amniotic fluid $52(13.7 \%)$ and 51 (13.3\%) respectively (Table 5 ).

\section{Factors associated with surgical site infection}

There were 13 independent variables in binary logistic regression which had $p<0.2$ and became candidate for multivariable regression: duration of labor, rupture of membrane before surgery, types of anesthesia, types of skin closure technique, types of abdominal incision, thickness of subcutaneous tissue, chorioamnionitis, duration of operation, diabetes mellitus, HIV/AIDS, urinary tract infection, pregnancy-induced hypertension, and estimated blood loss.

In the multivariable analysis, duration of labor, chorioamnionitis, pregnancy-induced hypertension, diabetes
Table 2 The distribution of medical-related characteristics of women underwent obstetrics surgery at FHCSH, Ethiopia, 2018 $(n=447)$

\begin{tabular}{|c|c|c|}
\hline Characteristics & Frequency $(n=447)$ & Percent (\%) \\
\hline \multicolumn{3}{|c|}{ Urinary tract infection } \\
\hline Yes & 12 & 2.7 \\
\hline No & 435 & 97.3 \\
\hline \multicolumn{3}{|l|}{ Pneumonia } \\
\hline Yes & 5 & 1.1 \\
\hline No & 442 & 98.9 \\
\hline \multicolumn{3}{|c|}{ Diabetes mellitus } \\
\hline Yes & 20 & 4.5 \\
\hline No & 427 & 95.5 \\
\hline \multicolumn{3}{|c|}{ Pregnancy induced hypertension } \\
\hline Yes & 47 & 10.5 \\
\hline No & 400 & 89.5 \\
\hline \multicolumn{3}{|l|}{ Anemia } \\
\hline Yes & 22 & 4.9 \\
\hline No & 425 & 95.1 \\
\hline \multicolumn{3}{|l|}{ HIV/AIDS } \\
\hline Yes & 13 & 2.9 \\
\hline No & 434 & 97.1 \\
\hline \multicolumn{3}{|l|}{ On ART } \\
\hline Yes & 11 & 84.6 \\
\hline No & 2 & 15.4 \\
\hline \multicolumn{3}{|c|}{ Deep vein thrombosis } \\
\hline Yes & 5 & 1.1 \\
\hline No & 442 & 98.9 \\
\hline \multicolumn{3}{|l|}{ Asthma } \\
\hline Yes & 4 & 0.9 \\
\hline No & 443 & 99.1 \\
\hline
\end{tabular}

mellitus, urinary tract infection, and thickness of subcutaneous tissue were significantly associated $(p<0.05)$ using backward stepwise regression.

Mothers who were on labor more than $24 \mathrm{~h}$ before surgery are 3.83 times more likely at risk for surgical site infections than less than $24 \mathrm{~h}$ on labor $[\mathrm{AOR}=5.25,95 \%$ $\mathrm{CI}=2.32-11.8]$.

Mothers who had chorioamnionitis are 3.73 times more likely to develop surgical site infection as compared to mothers who had not had chorioamnionitis [AOR $=3.73,95 \% \mathrm{CI}=1.22-11.4$ ].

Mothers who had pregnancy-induced hypertension are 6.4 more likely at risk for surgical site infection than mothers who had not had pregnancy-induced hypertension $[\mathrm{AOR}=6.4,95 \% \mathrm{CI}=2.26-18.2]$.

Mothers whose subcutaneous tissue thickness greater than $2 \mathrm{~cm}$ are 4.05 times more likely at risk for surgical site 
Table 3 The distribution of obstetrics related characteristics of women underwent obstetrics surgery at FHCSH, Ethiopia, 2018 $(n=447)$

\begin{tabular}{cll}
\hline Characteristics & Frequency $(n=447)$ & Percent (\%) \\
\hline Parity & & \\
1 & 111 & 24.8 \\
$2-4$ & 245 & 54.8 \\
$\geq 5$ & 91 & 20.4
\end{tabular}

ANC visit

$\begin{array}{ll}\text { Yes } & 340 \\ \text { No } & 107\end{array}$

Number of visits

$\begin{array}{ll}1 & 3 \\ 2-4 & 324 \\ \geq 5 & 13\end{array}$

Onset of labor

Induced

Spontaneous

Not in labor

Duration of labor

$\begin{array}{ll}\leq 24 h & 269 \\ >25 h & 72\end{array}$

Gestational age

$\begin{array}{ll}\text { Preterm } & 31 \\ \text { Term } & 360 \\ \text { Post term } & 5 \\ \text { Unknown } & 51\end{array}$

Number of vaginal examination

$\begin{array}{ll}\text { None } & 108 \\ 1-9 & 329 \\ \geq 10 & 10\end{array}$

Rupture of membrane

Yes

No

149

Duration of rupture of membrane

$$
\begin{aligned}
& <12 \mathrm{~h} \\
& \geq 12 \mathrm{~h}
\end{aligned}
$$

Presence of meconium

$\begin{array}{ll}\text { Yes } & 74 \\ \text { No } & 224\end{array}$

Chorioamnionitis

Yes

275
Table 4 The distribution of anesthesia- and operation-related characteristics of women underwent obstetrics surgery at FHCSH, Ethiopia, $2018(n=447)$

\begin{tabular}{lll}
\hline Characteristics & Frequency & Percent \\
\hline Preoperative hematocrit & & \\
$\leq 30 \%$ & 95 & 21.3 \\
$>30 \%$ & 352 & 78.7 \\
Type of operation & & \\
$\quad$ Cesarean section & 383 & 85.7 \\
Abdominal hysterectomy & 45 & 11 \\
Uterine repair & 19 & 4.3
\end{tabular}

Circumstance of operation

$\begin{array}{lll}\text { Elective } & 99 & 22.1 \\ \text { Emergency } & 348 & 77.9\end{array}$

Type of anesthesia

Spinal anesthesia

360

80.5

General anesthesia

87

Surgeon grade

Senior 12

2.7

Resident 4

159

35.6

Resident 3

55.9

Resident 2

5.8

Type of abdominal incision

Pfannenstiel

77.6

Vertical

Skin closure technique

Interrupted

Subcuticular

Thickness of subcutaneous tissue

$$
\leq 2 \mathrm{~cm}
$$

$>2 \mathrm{~cm}$

Postoperative hematocrit

$>30 \%$

Estimated blood lost

$$
\leq 11
$$

$>11$

Duration of operation

$$
\leq 1 \mathrm{~h}
$$

401

$>1 \mathrm{~h}$

Type of hysterectomy

TAH

84

STAH
38

46

7
16 
Table 4 The distribution of anesthesia- and operation-related characteristics of women underwent obstetrics surgery at FHCSH, Ethiopia, 2018 ( $n=447)$ (Continued)

\begin{tabular}{lll}
\hline Characteristics & Frequency & Percent \\
\hline Indication of hysterectomy & & \\
Postpartum hemorrhage & 12 & 26.7 \\
Adherent placenta & 10 & 22.2 \\
Uterine rupture & 23 & 51.1 \\
\hline
\end{tabular}

TAH total abdominal hysterectomy, STAH subtotal abdominal hysterectomy

infection than mothers whose subcutaneous tissue thickness is less than $2 \mathrm{~cm}[\mathrm{AOR}=4.05,95 \% \mathrm{CI}=1.75-9.4]$.

Those mothers who had diabetes mellitus are 3.99 more likely to develop surgical site infection than non-diabetic mother $[\mathrm{AOR}=3.99,95 \% \mathrm{CI}=1.03-15.5]$. The odds of surgical site infections were higher among mothers who had urinary tract infections than those who had not had urinary tract infections $[\mathrm{AOR}=7.78,95 \% \mathrm{CI}=1.4-43.25]$ (Table 6).

\section{Discussion}

The magnitude of surgical site infection following obstetrics surgery in this study was $9.4 \%(95 \% \mathrm{CI}=6.9-12.1)$. This finding is in line with the study finding at Vietnam (10.9\%) [10]. This could be due to all patients that received antibiotic treatment at the decision of the treating physician during the preoperative period in both study areas.

This finding is also in line with Sub-Saharan Africa countries (7.3\%), Jimma (11.4\%), Assela (9.4\%), and Tigray $(6.8 \%)[11-14]$. This might be due to the improvement of quality in surgical procedures that is almost similar (like preoperative antibiotics administration, the accessibility of surgical hand antiseptic product). An additional reason might be due to accessibility and

Table 5 The indication of cesarean section of women underwent obstetrics surgery in FHCSH, Ethiopia, $2018(n=383)$

\begin{tabular}{lll}
\hline Characteristics & $\begin{array}{l}\text { Frequency } \\
(n=383)\end{array}$ & Percent (\%) \\
\hline Indication of cesarean section & & \\
Non reassure fetal heart rate pattern & 60 & 15.7 \\
Cephalopelvic disproportion & 52 & 13.7 \\
Latent first stage of labor +GIIIMSAF & 51 & 13.3 \\
Malpresentation & 35 & 9.1 \\
Antepartum fetal hemorrhage & 22 & 5.7 \\
Failed induction & 13 & 3.4 \\
Obstructed labor & 7 & 1.8 \\
Two previous CS scar at term & 5 & 1.3 \\
Combination indications* & 138 & 36 \\
\hline
\end{tabular}

*Combination indication [previous cesarean section with $X$-factors, severe IUGR with unfavorable bishop score, fistula, uterine repair, cord accidents, declined VBAC, post term with X-factors prolonged LFSOL with grade II MSAF] quality of health service in Africa is low as compared to that of the developed countries.

The finding was higher than the value obtained from Brazil (1.44\%), Hungary (3.6\%) Pakistan (5.8\%), and Rwanda (4.9\%) [15-17]. The difference might be the flow of the patients, and the number of beds in the maternity ward was significantly disproportional, causing overcrowding and making the environment safe for nosocomial postoperative infections. Another possible reason could be due to poor dietary style and poor personal hygiene due to low socioeconomic capacity which leads women to be vulnerable to nosocomial postoperative complications.

The finding was lower than the value obtained from India (24.2\%), Zimbabwe (29\%), and Uganda (16.4\%) [17-19]. This discrepancy could be due to since this study was cross-sectional study, there was no post discharge follow-up and patients may develop SSI and may seek treatment nearby health facilities other than the study area.

In this study, duration of labor more than $24 \mathrm{~h}$ was an independent risk factor for surgical site infection. This risk factor was similar to findings done in the USA, Nigeria, Kenya, Jimma, and Assela [12, 14, 20-22]. The possible explanation could be due to the repeated attempt of vaginal examination in prolonged labor enhances ascending infection.

Diabetes mellitus was noted to be another independent risk factor for surgical site infection. It is further supported by other studies done in India, Nizwa, and Nigeria [22-24]. This could be attributed to poor peripheral oxygen supply due to metabolic derangements and altered inflammatory response after surgery.

In this study, pregnancy-induced hypertension was found to be significantly associated with surgical site infection. Similar findings have been reported by other studies done in India, Nizwa, and Nigeria [22-24]. The possible explanation could be due to vascular disruption and high oxygen consumption by metabolically active cells that lead to oxygen depletion and wound becoming quite hypoxic.

In this study, the magnitude of surgical site infection was higher compared to the standard CDC guidelines of surgical site infection [6]. This might be due to the shortage of personal protective equipment for all obstetric procedures, lack of potent antibiotics for prophylaxis, lack of experience sharing of the surgeon with developed countries, unable to implement WHO checklists due to shortage of resources and infrastructure as well as poor accessibility of the health facility in Ethiopia as well as in Sub-Saharan African countries. To minimize these problems, WHO and CDC surgical checklists should be implemented.

Patients who had chorioamnionitis were an independent risk factor for developing surgical site infection. 
Table 6 The bivariate and multivariable association of surgical site infections and independent factors among women who underwent obstetrics surgery at FHRH, Ethiopia, $2018(n=447)$

\begin{tabular}{|c|c|c|c|c|c|}
\hline \multirow[t]{2}{*}{ Characteristics } & \multicolumn{2}{|c|}{ Surgical site infection } & \multirow[t]{2}{*}{$\operatorname{COR}(95 \% \mathrm{Cl})$} & \multirow[t]{2}{*}{$\mathrm{AOR}(95 \% \mathrm{Cl})$} & \multirow{2}{*}{$\begin{array}{l}p \\
\text { value }\end{array}$} \\
\hline & $\overline{\text { Yes }}$ & $\mathrm{No}$ & & & \\
\hline \multicolumn{6}{|l|}{ Duration of labor } \\
\hline$\leq 24 \mathrm{~h}$ & $23(54.8 \%)$ & $246(82.2)$ & 1 & 1 & \\
\hline$\geq 25 \mathrm{~h}$ & $19(45.2 \%)$ & $53(17.8 \%)$ & $3.83(1.68-7.84)$ & $5.25(2.32-11.8)$ & $0.001^{* *}$ \\
\hline \multicolumn{6}{|c|}{ Duration of operation } \\
\hline$\leq 1 \mathrm{~h}$ & 34 (81\%) & 367 (90.6) & 1 & 1 & \\
\hline$>1 \mathrm{~h}$ & $8(19 \%)$ & $38(9.4 \%)$ & $2.27(0.98-5.26)$ & $0.5(0.15-1.68)$ & 0.26 \\
\hline \multicolumn{6}{|c|}{ Duration of ROM } \\
\hline$<12 \mathrm{~h}$ & $9(22.5 \%)$ & $118(45.7)$ & 1 & 1 & \\
\hline$\geq 12 \mathrm{~h}$ & 31 (77.5\%) & $140(54.3)$ & $2.9(1.32-6.34)$ & $1.98(0.76-5.1)$ & 0.16 \\
\hline \multicolumn{6}{|c|}{ Chorioamnionitis } \\
\hline Yes & 9 (22.5\%) & $14(5.4)$ & $5.06(2.02 .12)$. & $3.73(1.22-11.4)$ & $0.021^{* *}$ \\
\hline No & $3177.5(\%)$ & $244(94.6)$ & 1 & 1 & \\
\hline \multicolumn{6}{|l|}{ Type of incision } \\
\hline Pfannenstiel & $22(52.4 \%)$ & $325(80.2 \%)$ & 1 & 1 & \\
\hline Vertical & $20(47.6 \%)$ & $80(19.8 \%)$ & $3.69(1.92-7.09)$ & $1.6(0.67-3.74)$ & 0.26 \\
\hline \multicolumn{6}{|l|}{ DM } \\
\hline yes & $5(19 \%)$ & $15(3.7)$ & $3.5(1.2-10.2)$ & $3.99(1.03-15.5)$ & $0.045^{* *}$ \\
\hline No & 37 (88.1\%) & $390(96.3)$ & 1 & 1 & \\
\hline \multicolumn{6}{|c|}{ Skin closure technique } \\
\hline Interrupted & $10(23.8 \%)$ & $30(7.4)$ & $3.9(1.75-8.7)$ & $0.57(0.16-2.03)$ & 0.39 \\
\hline Subcuticular & $32(76.2 \%)$ & $375(92.6)$ & 1 & 1 & \\
\hline \multicolumn{6}{|c|}{ Type of anesthesia } \\
\hline SA & $27(64.3 \%)$ & $333(82.2)$ & 1 & 1 & \\
\hline GA & $15(35.7 \%)$ & $72(17.8 \%)$ & $2.56(1.3-5.07)$ & $1.34(0.35-5.1)$ & 0.66 \\
\hline \multicolumn{6}{|l|}{$\mathrm{PIH}$} \\
\hline yes & $11(26.2 \%)$ & $36(8.8 \%)$ & $3.63(1.68-7.84)$ & $6.4(2.26-18.2)$ & $0.000^{* *}$ \\
\hline No & $31(75.8 \%)$ & $369(91.2)$ & 1 & 1 & \\
\hline \multicolumn{6}{|c|}{ Thickness of subcutaneous tissue } \\
\hline$\leq 2 \mathrm{~cm}$ & $26(61.9 \%)$ & $343(84.4)$ & 1 & 1 & \\
\hline$>2 \mathrm{~cm}$ & $16(38.1 \%)$ & $62(15.6)$ & $3.4(1.72-6.71)$ & $4.05(1.75-9.4)$ & $0.001^{* *}$ \\
\hline \multicolumn{6}{|l|}{ EBL } \\
\hline$\leq 1 \mathrm{~L}$ & $36(85.7 \%)$ & $378(93.3)$ & $2.3(0.9-6)$ & $1.3(0.26-6.6)$ & 0.74 \\
\hline$>1 \mathrm{~L}$ & $6(14.3 \%)$ & $27(6.7 \%)$ & 1 & 1 & \\
\hline \multicolumn{6}{|l|}{ UTI } \\
\hline yes & $7(1.7)$ & $5(11.9)$ & 1 & 1 & \\
\hline No & $398(98.3)$ & $37(88.1)$ & $7.68(2.3-25.4)$ & $7.78(1.4-43.25)$ & $0.019^{* *}$ \\
\hline \multicolumn{6}{|l|}{ HIV/AIDS } \\
\hline Yes & $8(19.7)$ & $5(11.9)$ & 1 & 1 & \\
\hline No & $397(80.3)$ & $37(88.1)$ & $6.7(2.1-21.5)$ & $3.5(0.76-16.5)$ & 0.1 \\
\hline
\end{tabular}

\footnotetext{
${ }^{*}$ stands for very significant
} 
Similar findings have been reported in the USA, Jimma and Assela studies [12, 14, 21]. This might be explained by the fact that intact membrane serves as a barrier to ascending infections from the lower genital tract to the uterine cavity. An additional explanation could be due to iatrogenic contamination of the peritoneum during surgery.

In this study, urinary tract infection was associated with surgical site infection. Similar findings have been reported in Nizwa and Nigeria [22, 24]. This could be due to bacterial colonization that predominantly decreases wound-healing process and increases systemic infection.

The thickness of subcutaneous tissue more than $2 \mathrm{~cm}$ was an independent risk factor for surgical site infection in this study. Similar findings have been reported by a study done in the USA at Washington [21]. This might be due to poor vascularity of the subcutaneous tissue, serous fluid collection, and hematoma formation in an obese woman.

\section{Conclusion}

It has been revealed that the magnitude of surgical site infection following obstetrics surgery rate was higher compared to the standard CDC guidelines of surgical site infection. Duration of labor stays more than $24 \mathrm{~h}$, chorioamnionitis, pregnancy-induced hypertension, urinary tract infections, diabetes mellitus, and thickness of subcutaneous tissue more than $2 \mathrm{~cm}$ were associated with surgical site infections. Implementing a sterile environment and aseptic techniques in all surgical procedures, use of WHO surgical safety checklist would become visible to be a very important intervention to reduce surgical site infections. In addition to complication readiness, birth preparedness and setting their antenatal care follow-up at the hospital with special and targeted services can reduce the magnitude of surgical site infection.

\section{Limitation}

This study shares the limitations of cross-sectional studies and hence may not be possible to establish a temporal relationship between surgical site infections and explanatory variables.

\section{Abbreviations \\ ACOG: American College of Obstetrics and Gynecology; CD: Cesarean delivery; CDC: Communicable disease control; SSI: Surgical site infection; WHO: World Health Organization}

\section{Acknowledgements}

We would like to thank the ethical review board committee of Bahirdar University College of Medicine and Health Sciences for giving ethical clearance. Also, our deep gratitude extends to Felegehiwot Comprehensive Specialized Hospital for their cooperative and giving information for our input information.

Last but not least, we would like to thank data collectors and supervisor for doing their responsibility honestly and timely submission and collection of the data.
Funding

Not applicable

Availability of data and materials

All relevant data are within the manuscript.

\section{Authors' contributions}

GG wrote the proposal, participated in the data collection, analyzed the data, and drafted the paper. AA, SS, and DA approved the proposal with some revisions, participated in the data collection, analysis, and manuscript writing. All authors read and approved the final manuscript.

\section{Ethics approval and consent to participate}

Ethical clearance was obtained from the ethical review committee of Bahir Dar University College of Medicine and Health Science. Permission letter was obtained from Amhara Regional Health Bureau and also asked from Felegehiwot Comprehensive Specialized Hospital.

Since the study was based on secondary data, there was no direct contact with patients. So anonymity was maintained by using identity numbers instead of patient names. Besides, all the data abstracted was kept confidential and not used for any other purposes than the stated research objective.

\section{Consent for publication}

Not applicable.

\section{Competing interests}

The authors declare that they have no competing interests.

\section{Publisher's Note}

Springer Nature remains neutral with regard to jurisdictional claims in published maps and institutional affiliations.

\section{Author details}

${ }^{1}$ Department of Midwifery, Faculty of Health Sciences, Woldia University, Woldia, Ethiopia. ${ }^{2}$ Department of Midwifery, College of Medicine and Health Sciences, Bahir Dar University, Bahir Dar, Ethiopia. ${ }^{3}$ Department of Midwifery, College of Medicine and Health Sciences, Debre Tabor University, Debre Tabor, Ethiopia.

Received: 10 October 2018 Accepted: 13 November 2018

Published online: 14 December 2018

\section{References}

1. Berhan Y, Berhan A. Causes of maternal mortality in Ethiopia: a significant decline in abortion related death. Ethiop J Health Sci. 2014;24 Suppl:15-28.

2. Smith MA, Dahlen NR. Clinical practice guideline surgical site infection prevention. Orthop Nurs. 2013;32:242-8.

3. Daniel A, Zemanuel T. Hospital acquired surgical site and catheter related urinary tract infections among patients admitted in Mekele hospital, Mekele, Tigray, Ethiopia. AAU libraries electronic thesis and dissertation. 2008.

4. Brunicardi FC. Schwartz manual of surgery. United States; 2006.

5. WHO. SUSP project in African surgical departments. 2014.

6. WHO. Global Guidelines For The Prevention of Surgical site infection Geneva, Switzerland. WHO library cataloguing-in-publication data. 2016.

7. Wondemagegn Mulu GK, Beyene G, Damtie M. Associated risk factors for postoperative nosocomial infections among patients admitted at Felege Hiwot Referral Hospital, Bahir Dar, North West Ethiopia. Clin Med Res. 2013;2:140-7.

8. Saeed KB, Greene RA, Corcoran P, O'Neill SM. Incidence of surgical site infection following caesarean section: a systematic review and meta-analysis protocol. BMJ Open. 2017;7(1):e013037.

9. Victor D, Revathi G, Sam K, Abdi H, Asad R, Andrew K. Pattern of pathogens and their sensitivity isolated from surgical site infections at the Aga Khan University Hospital, Nairobi, Kenya. Ethiop J Health Sci. 2013;23(2):141-9.

10. Varkonyi I, Makai I, Papdine Nyiri G, Bacsko G, Kardos L. Postoperative surveillance of wound infection after cesarean section at Kenezy Hospital, Debrecen, Hungary. Orv Hetil. 2011;1(152):14-22.

11. Chu K, Maine R, Trelles M. Cesarean section surgical site infections in subSaharan Africa: a multi-country study from Medecins Sans Frontieres. World J Surg. 2015;39(2):350-5. 
12. Mamo T, Abebe TW, Chichiabellu TY, Anjulo AA. Risk factors for surgical site infections in obstetrics: a retrospective study in an Ethiopian referral hospital. Patient Saf Surg. 2017;11(1):24.

13. Gelaw KA, Aweke AM, Astawesegn FH, Demissie BW, Zeleke LB. Surgical site infection and its associated factors following cesarean section: a cross sectional study from a public hospital in Ethiopia. Patient Saf Surg. 2017;11:18.

14. Amenu D, Belachew T, Araya F. Surgical site infection rate and risk factors among obstetric cases of Jimma University Specialized Hospital, Southwest Ethiopia. Ethiop J Health Sci. 2011;21(2):91-100.

15. Zimlichman E, Henderson D, Tamir O, et al. Health care-associated infections: a meta-analysis of costs and financial impact on the US health care system. JAMA Intern Med. 2013;173(22):2039-46.

16. Farret TCF, Dallé J, Monteiro VS, Riche CWW, Antonello VS. Risk factors for surgical site infection following cesarean section in a Brazilian Women's Hospital: a case-control study. Braz J Infect Dis. 2015;19(2):113-7.

17. Bizimana K, Ndoli J, Bayingana C, Baluhe I, Gilson GJ, Habimana E. Prevalence and risk factors for post cesarean delivery surgical site infection in a teaching hospital setting in rural Rwanda. Int J Curr Microbiol App Sci. 2016;5:631-41.

18. De D, Saxena S, Mehta G, Yadav R, Dutta R. Risk factor analysis and microbial etiology of surgical site infections following lower segment caesarean section. Int J Antibiot. 2013;2013:1-6.

19. Nguyen D, MacLeod WB, Phung DC, Cong QT, Nguy VH, Van Nguyen H, et al. Incidence and predictors of surgical-site infections in Vietnam. Infection control and hospital epidemiology. 2001;22(8):485-92. PubMed PMID: 11700875. Epub 2001/11/10. eng.

20. MGONGO DOI. Post caeserean section wound sepsis at Mnazi Mmoja Hospital; 2010. p. 8.

21. Kawakita T, Landy HJ. Surgical site infections after cesarean delivery: epidemiology, prevention and treatment. Paediatr Perinat Epidemiol. 2017;3:12.

22. Jido T, Garba I. Surgical-site infection following cesarean section in Kano, Nigeria. Ann Med Health Sci Res. 2012;2(1):33-6.

23. Pathak A, Lundborg CS, Mahadik K, Swami MB, Sharma M, Roy PK, et al. Incidence and risk factors for surgical site infections in obstetric and gynecological surgeries from a teaching hospital in rural India. Antimicrob Resist Infect Control. 2017:6(1):66

24. Laloto TL, Gemeda DH, Abdella SH. Incidence and predictors of surgical site infection in Ethiopia: prospective cohort. BMC Infect Dis. 2017;17(1):119.

Ready to submit your research? Choose BMC and benefit from:

- fast, convenient online submission

- thorough peer review by experienced researchers in your field

- rapid publication on acceptance

- support for research data, including large and complex data types

- gold Open Access which fosters wider collaboration and increased citations

- maximum visibility for your research: over $100 \mathrm{M}$ website views per year

At $\mathrm{BMC}$, research is always in progress.

Learn more biomedcentral.com/submissions 